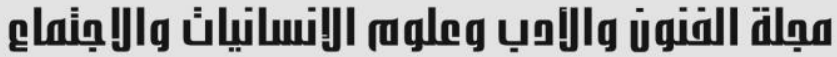

Journal of Arts, Literature, Humanities and Social Sciences www.jalhss.com

\section{تحليل الخطاب الأدبي في ضوء النظريات التداولية 1 (دراسة ومقاريات)}

أستاذ الأدمد الأمين الثيخ المسيخ أحمد قسم اللغة العربية وآدابها - جامعة القصيم ـ المبادئ المملكة العربية السعودية البريد الالكتروني: alhayba@gmail.com

د. عبد الله بن حمود الفوزان

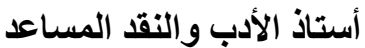
قسم اللغة العربية وآدابها - جامعة القصيم ـ المملكة العربية السعودية

يسعى البحث إلى عرض فكرة إخضاع الخطاب الأدبي والثعري خاصة إلى التحليل عن طريق إجراءات النظريات التداولية، وبما أن الأمر قد يبدو صعباً من الوهلة الأولى، بحكم كثرة هذه النظريات من جهة وبحكم عدم التسليم بملاءمتها للخطاب الأدبي عامة والخطاب الثعري خاصة، إلا أن البحث لم يغفل جميع هذه الآر اء، بحيث طرح التساؤل حول مدى جدو ائية هذه الفكرة من الأساس، فالثتعر تعالي على اللغة العادية والتداولية منهج ترعرع في أحضن الفلسفة النفعية، و التي تقيس الأشياء بمدى فائدتها.

لكن البحث أيضا في نفس الوقت يذّكر بمحورية الثعر في القافة العربية، وبأهمية السياق، في التراث العربي، الأمر يجعل دراسة الخطاب الثعري دون النظر إلى الحيثيات التي ولد فيها، تعتبر دراسة ناقصة، ومن هنا كان للتداولية أن تحط رحالها في هذا الخضم، فاقترح البحث - بعد عدة توطئات ـ مجموعة من الإجراءات، التي دهي

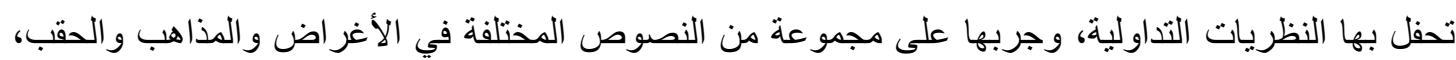

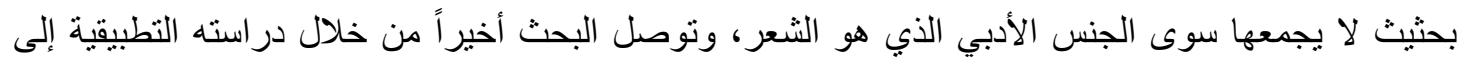
مجمو عة من النتائج، يمكن أن يُستفاد منها في المستقبل، أو يُينى عليها في در اسات، لا حقة. الكلمات المفتاحية: الخطاب الأدبي، النظريات التداولية. 


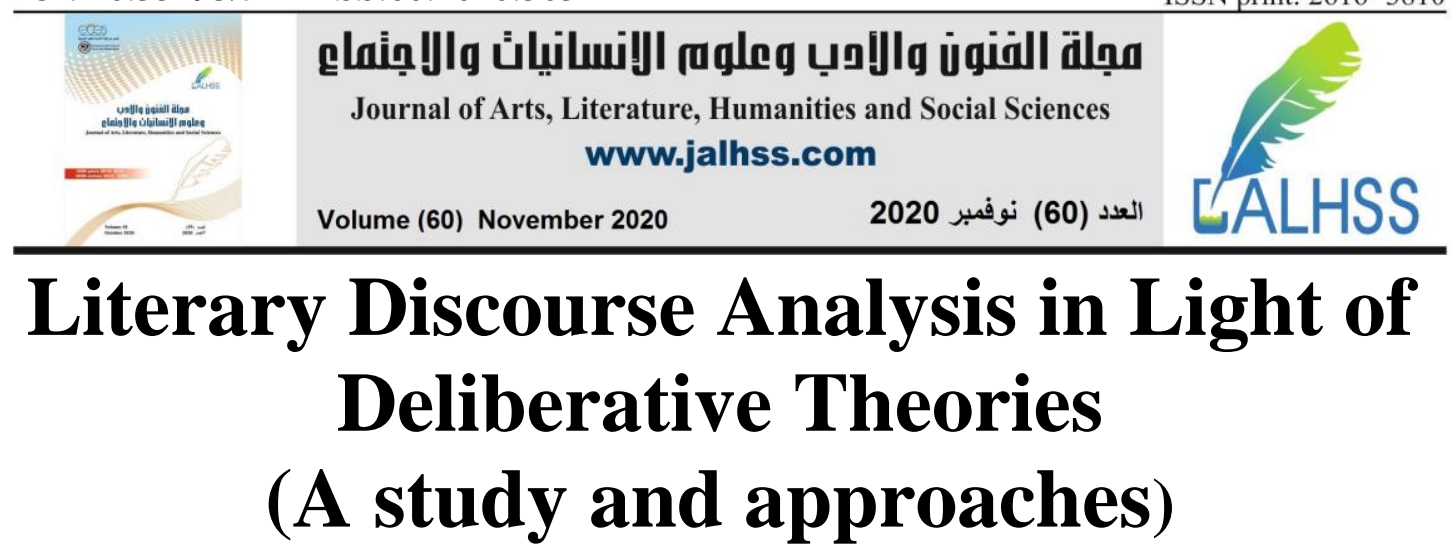

\author{
Dr. Mohammed Al-Amin Sheikh Ahmed \\ Assistant Professor of Literature and Criticism \\ Department of Arabic Language and Literature - Qassim University - KSA \\ Email: alhayba@gmail.com \\ Dr. Abdullah bin Hamoud Al-Fawzan \\ Assistant Professor of Literature and Criticism \\ Department of Arabic Language and Literature - Qassim University - KSA
}

\begin{abstract}
The present study seeks to present the idea of subjecting the literary and poetic discourse especially to the analysis through the procedures of the deliberative theories; since it may initially seem difficult, because of the large number of these theories on the one hand and the lack of recognition of their suitability to the literary discourse in general and the poetic discourse in particular on the other, all these views were not neglected in that a question, on the feasibility of this idea was raised here. Needless to say, poetry does have transcendence over ordinary language, and deliberative curriculum has grown up in the warm lap of utilitarian philosophy, which considers the usefulness and effectiveness of things as essential criteria for measuring them.

The study does, however, simultaneously refer to the centrality of poetry in the Arabic language, and the significance of context in the Arab heritage; this makes the study of poetic discourse without looking at the rationales in which it was born incomplete. That is basically how deliberation had cropped up. Thus, the current study proposed, of course after several introductions, a series of procedures proponent to deliberative theories, and applied them to a variety of texts of different purposes, doctrines and periods the common thing to which is poetry. This study, which is applied in nature, concluded with a set of results that would certainly be of use to all concerned and based on which subsequent studies can be built.
\end{abstract}

Keywords: literary discourse, deliberative theories. 


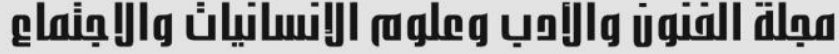

Journal of Arts, Literature, Humanities and Social Sciences www.jalhss.com

تحاول هذه الأوراق الإجابة عن بعض التساؤلات التي طرحت نفسها بإلحاح أو طرحها بعض الباحثين و المرتمين

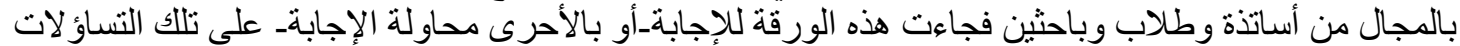

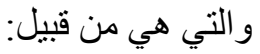
• ما مدى استفادتنا -في قر اعتتا للشعر - من منهج ترعرع في أحضان فلسفية نفعية، مهنمة بدراسة الخطاب

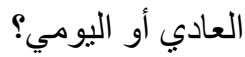

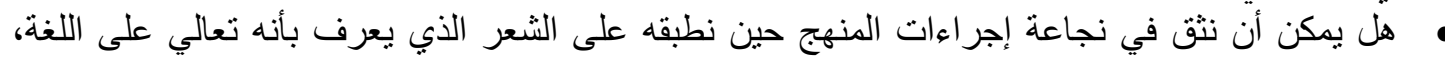

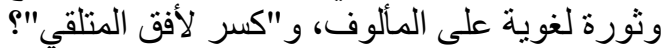

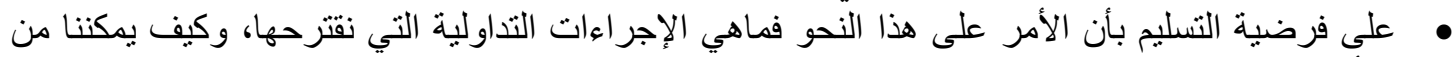

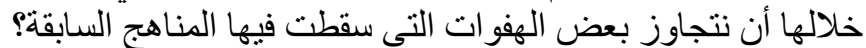

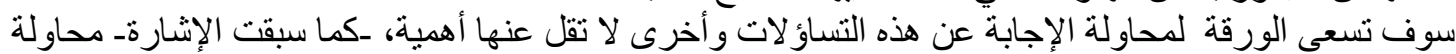

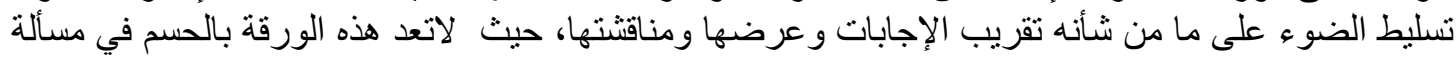

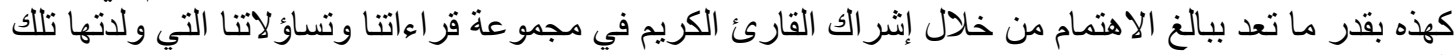

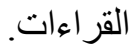
سوف تمر الورقة -ابر غم محدوديتها- بمر احل متنو عة ومتباينة وقد لا يكون الانتقال بينها انتقالا سلساً أو معتادا

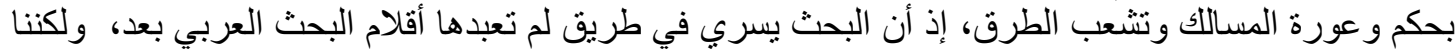

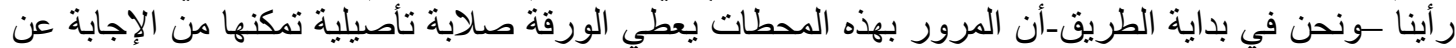

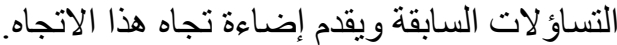

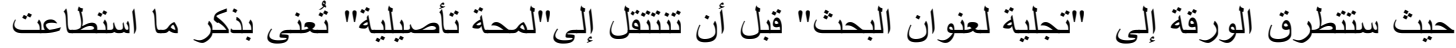

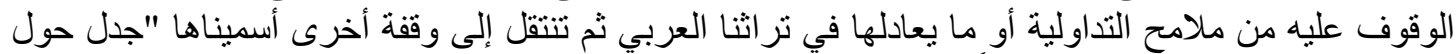

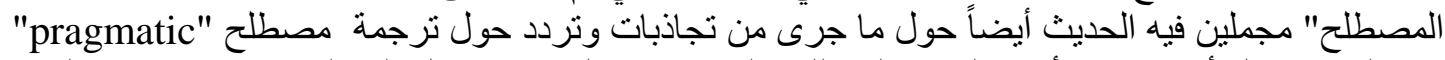

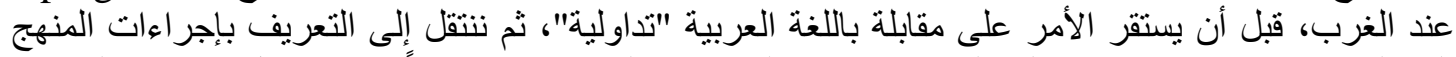

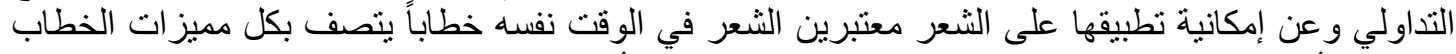

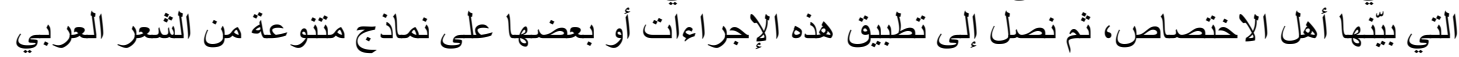
الفصيح، محاولين الإجابة على ما استعطنا من التساؤ لات السابقة.

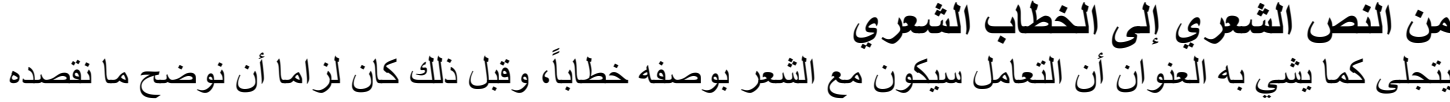

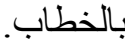

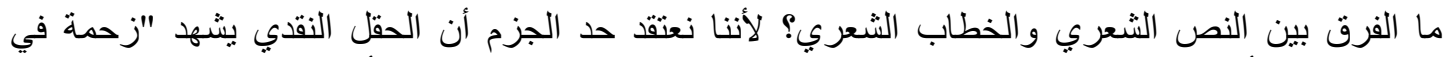
المصطلحات" أدت إلى فوضى في المفاهيم وضبابية في الفهم، تحاول الدراسة أن تتجنبها من خلال ضلن ضبط المفاهيم و المصطلحات التي تستخدمها.

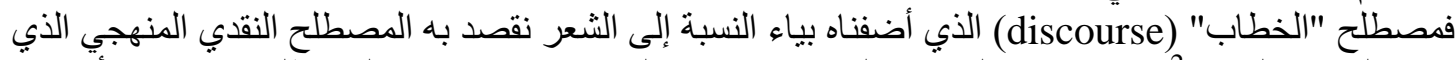

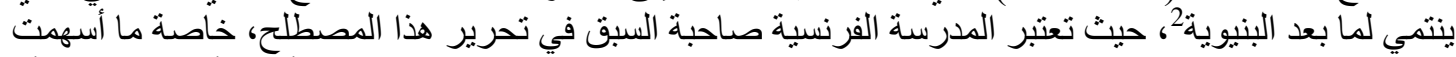

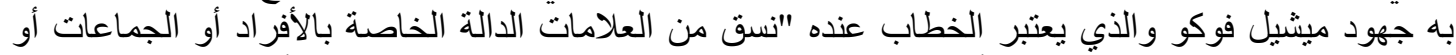

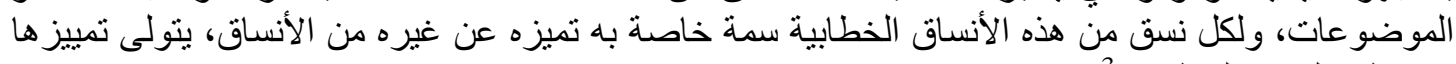

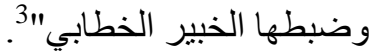

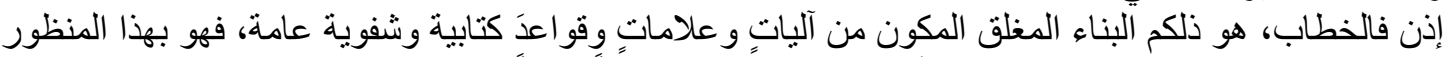

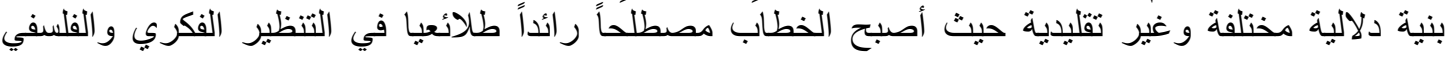

323 مختار الفجاري: مناهج البحث اللغوي في العصر الحديث، دار الزمان، 2012، ص:142 


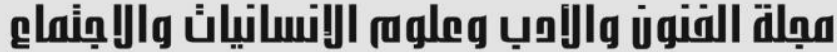

Journal of Arts, Literature, Humanities and Social Sciences www.jalhss.com

Volume (60) November 2020

العدد (60) نوفمبر 2020

و النقدي لما بعد البنيوية، مع أن هناك طائفة ليست بالقليلة من الباحثين الكلاسيكيين الداعين للتمسك بالقديم

ينسبون نشأة الخطاب كمصطلح إلى البنيوية.

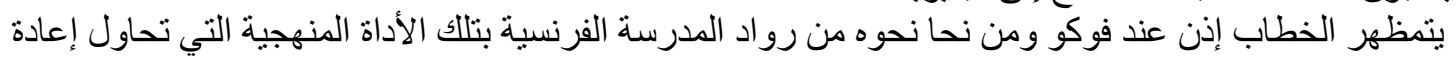

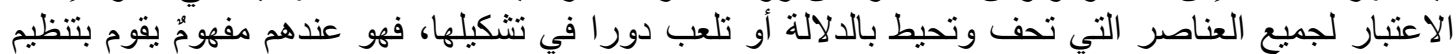

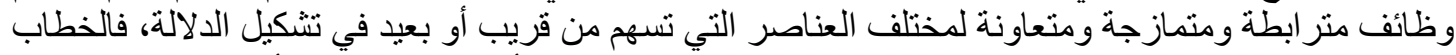

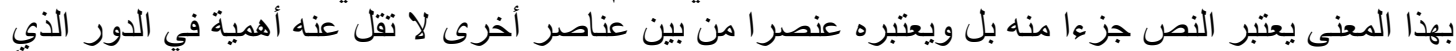
يلعبه كل منها لتشكيل الدلالة أو المعنى مثل النص و السياق و التناريخ وبقية الحيثيات التي ترسم ملامح الدلالة أياً كانت طبيعنها.

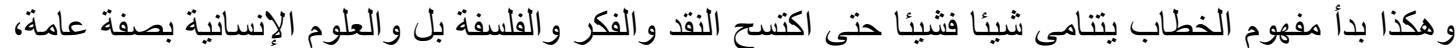

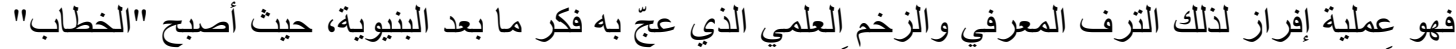

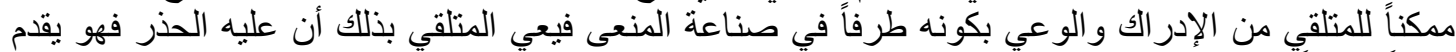

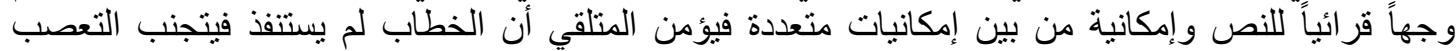

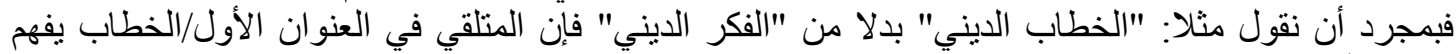

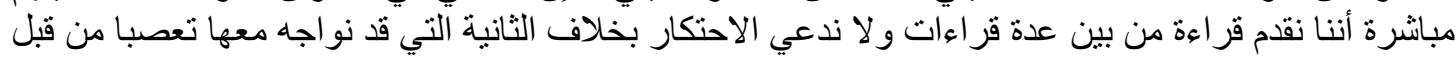

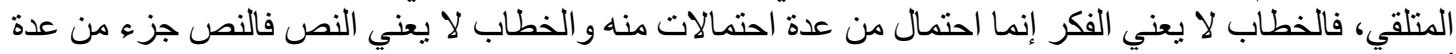

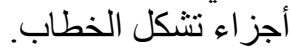
فالخطاب في النقد الحديث هو انفتاح وهروب من مجال الفهم المطلق في الفكر إلى مجال الفهم النسبي فالخطاب

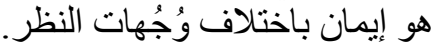

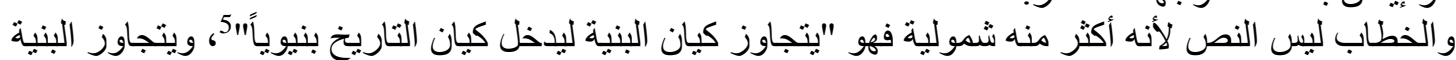

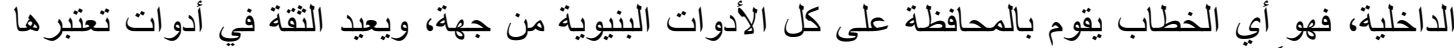
البنيو ية تقليديةً، من جهة أخرى.

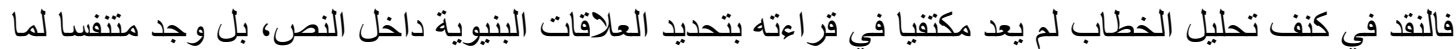

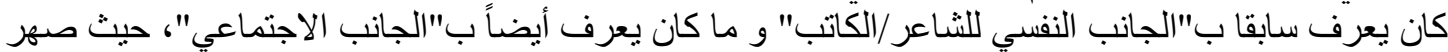

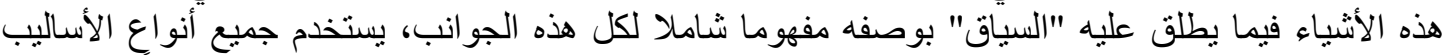

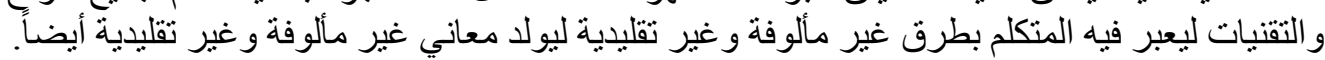

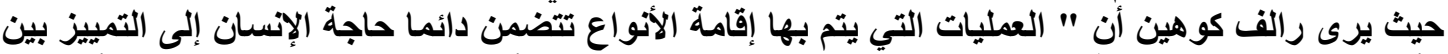

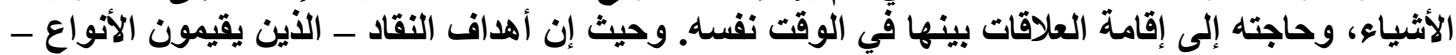

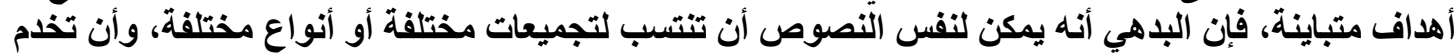

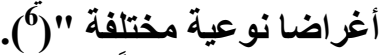

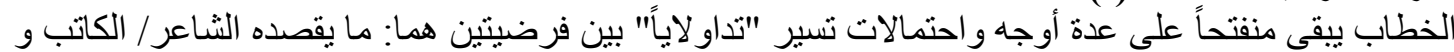

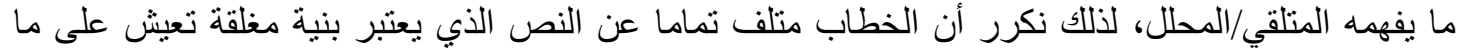

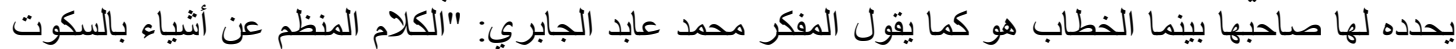

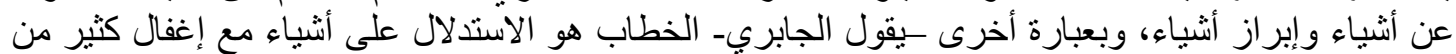

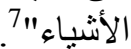

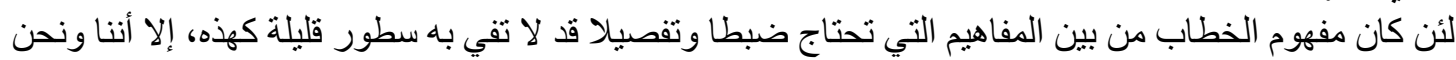

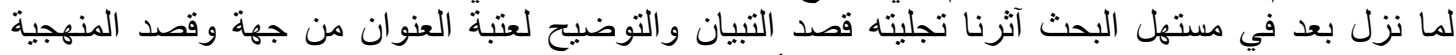

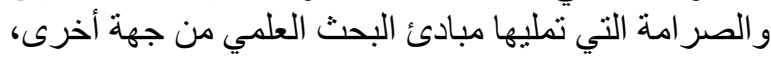

4 ينظر :الفجاري، مختار، مفهوم الخطاب بين مرجعه الأصلي الغربي وتأصيله في اللغة العربية ، مجلة جامعة

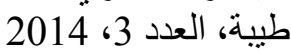

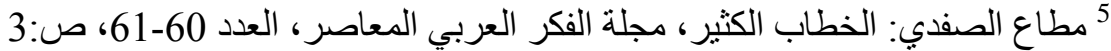

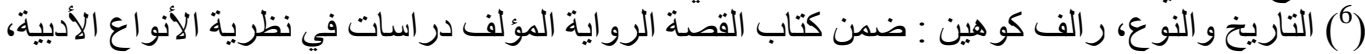

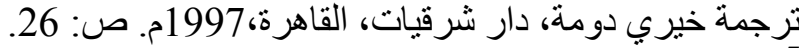

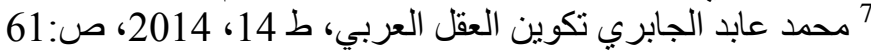




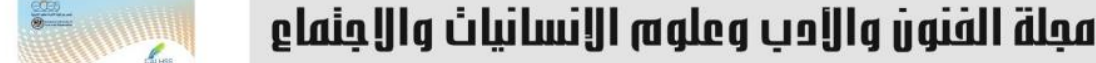

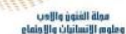 \\ Journal of Arts, Literature, Humanities and Social Sciences www.jalhss.com \\ Volume (60) November 2020 \\ العدد (60) نوفمبر 2020 (20)}

فالخطاب الثعري -باختصار- حسب المفهوم الذي بسعى ذووه8 لتحديده ليس الكلام الصريح -كما سبقت

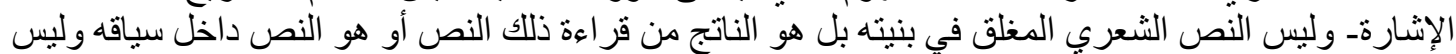
الفكر المطلق إنما هو إمكانية من ذللك الفكر.

\section{نحن نمارس التداولية قبل أن نعرفها}

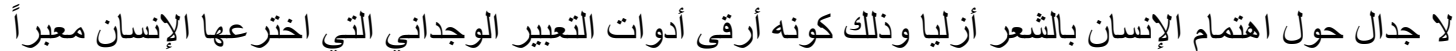

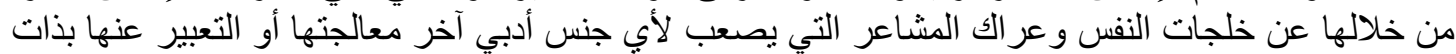

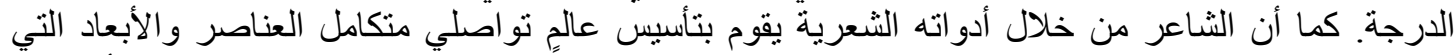

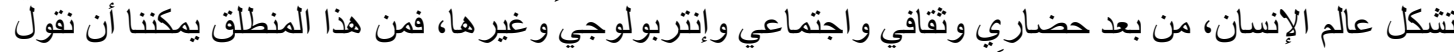

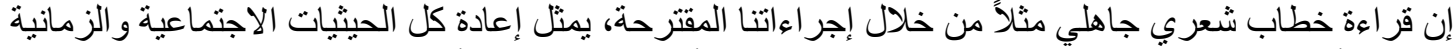

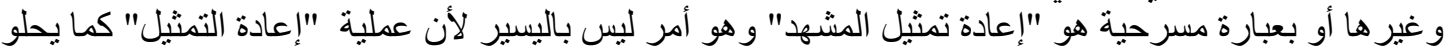

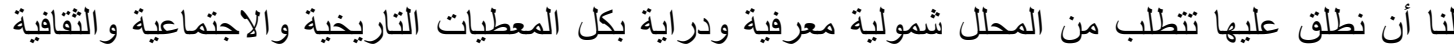

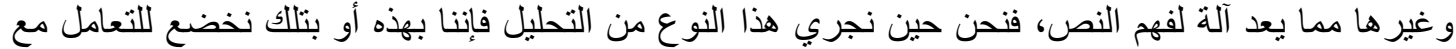

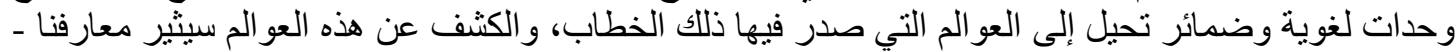

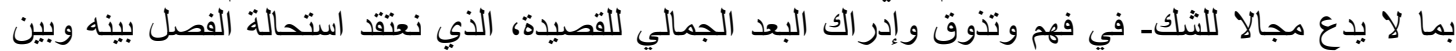

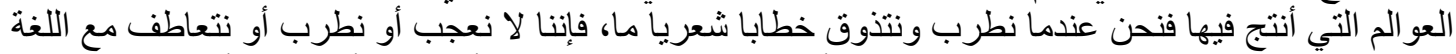

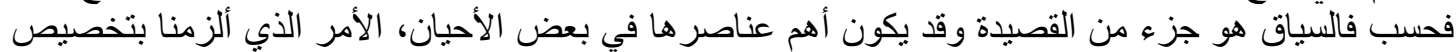

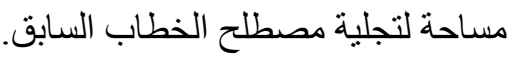

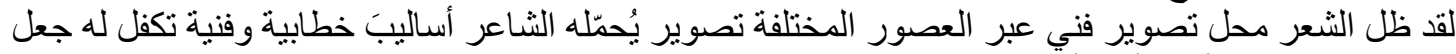

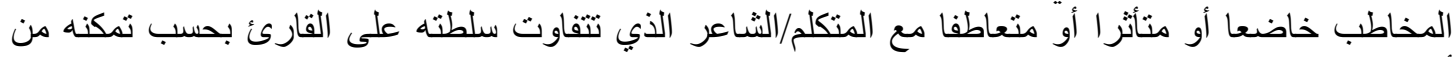

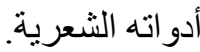

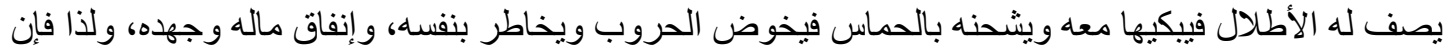

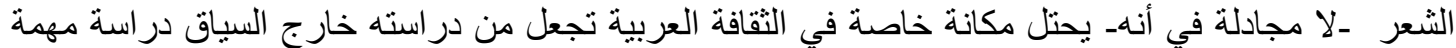

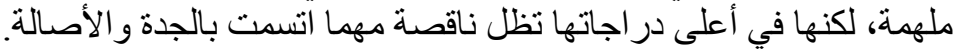

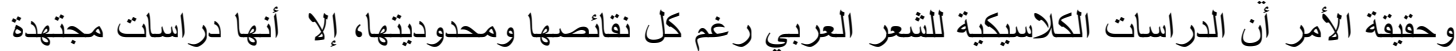

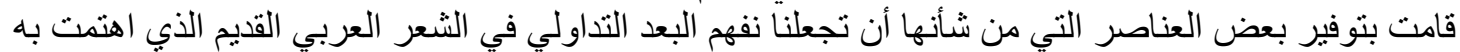

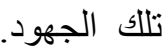

فمن ذلك الاهتمام بمناسبة القصيدة والظروف و الحيثيات، كالمحيط والبيئة و الزمن و والمناسبة التي ولد فيها

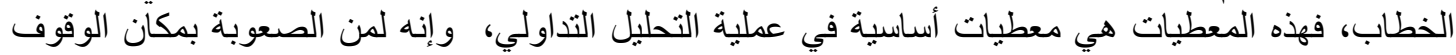
على البعد الجمالي في الخطاب الثنعري دون تلبس السياق الذي الذي ولد فيه ذلك التك الخطاب.

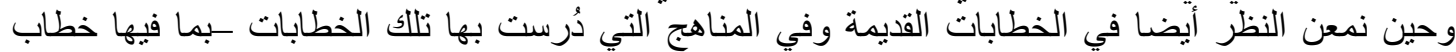

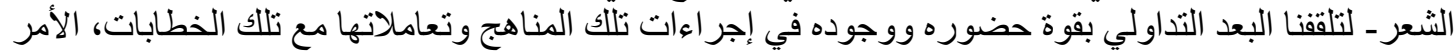

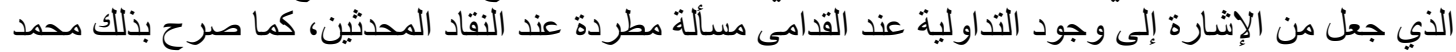

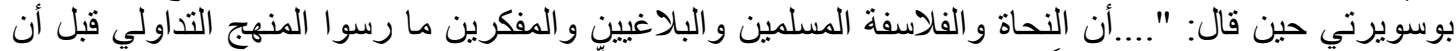

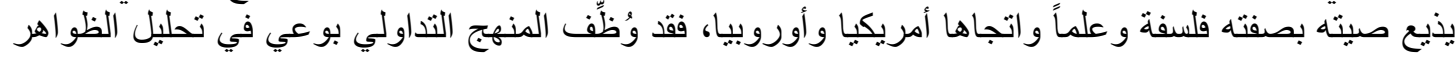

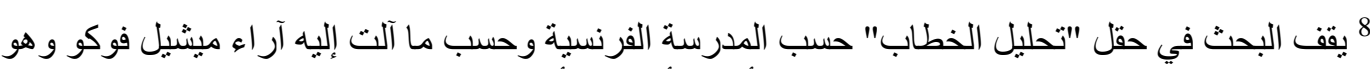
الر ائد في هذا المجال، إلى تصنيف الخطاب إلى أربعة أصناف أثنار إليها الدكتور مختار فجاري في كتابه

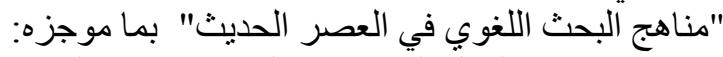

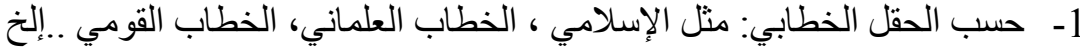
2- - حسب نمط الخطاب: مثل الخطاب الصحفي، أو الخطاب الأدبي، أو الخطاب الخطاب الإداري.

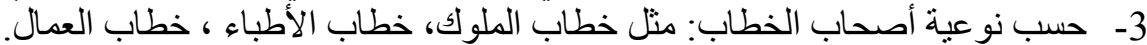
4- حسب وظيفة الكلام: مثل الخطاب السجالي، الخطاب الإلز امي ..إلخ. 


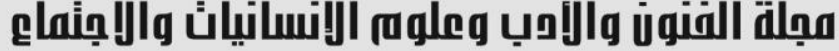

و العلاقات المتنوعة"(9). و هو الأمر الذي نجده عند المفسرين واهتمادهم بأسباب النزول فقد كان "...المفسرون

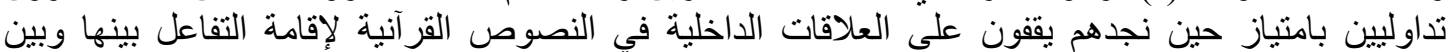

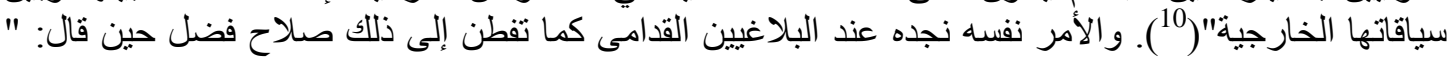

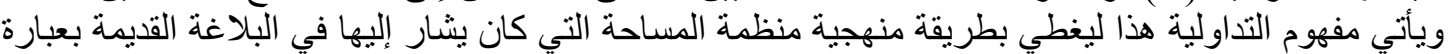

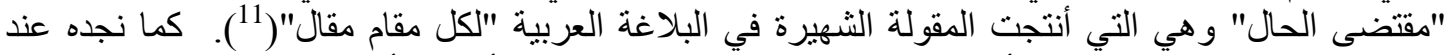

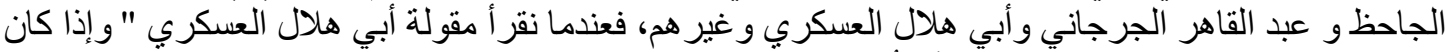

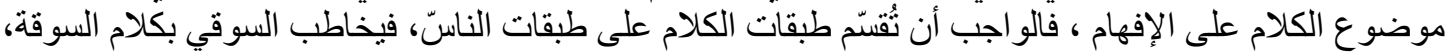

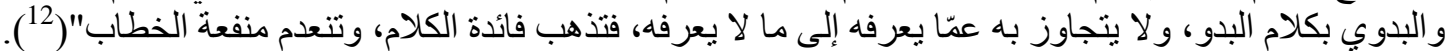

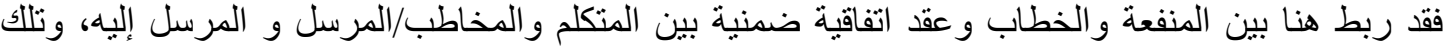

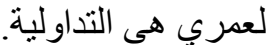

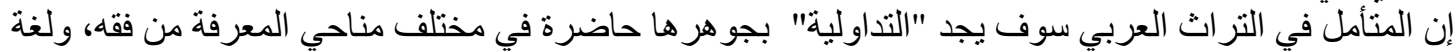
و أدب وأصول وتفي لأنسير و غير ها، الأمر الذي يحتم حضور ها في الشعر الذي اعتبره النقاد و المؤرخون سجل الحياة

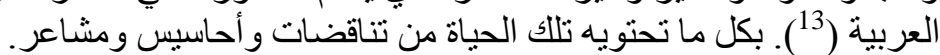

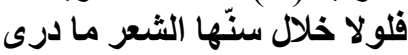

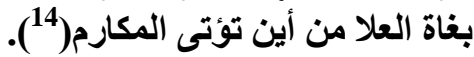

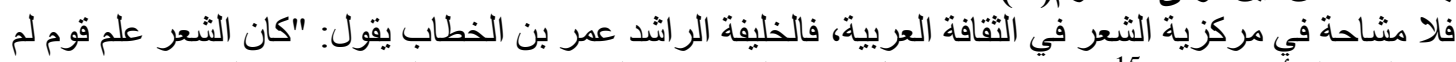

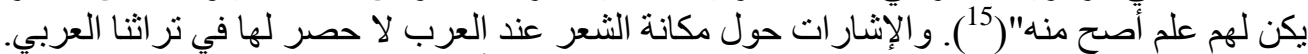

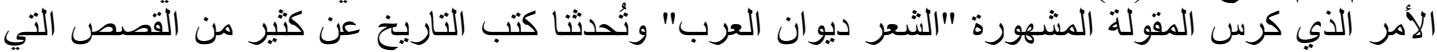

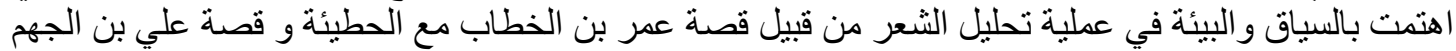

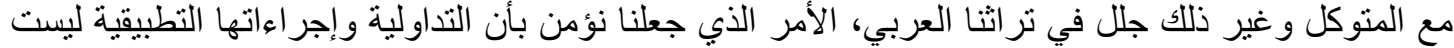

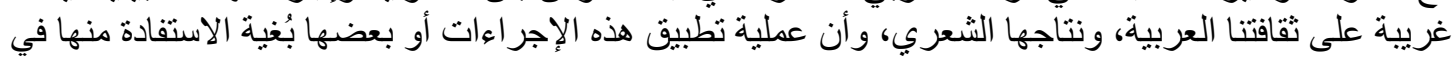

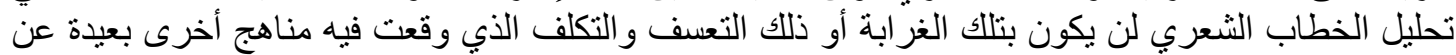

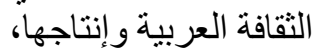

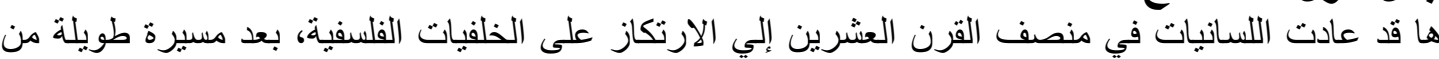

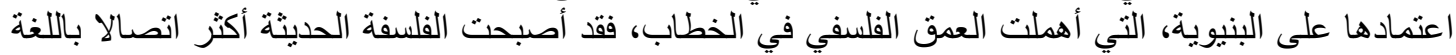

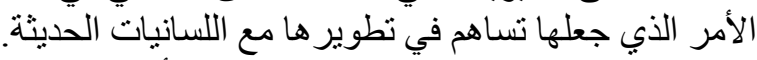

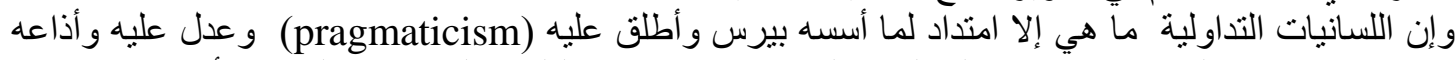

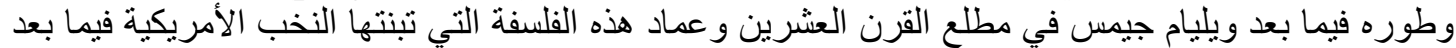

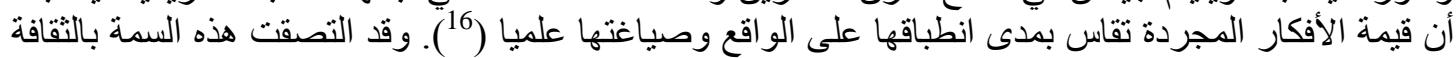

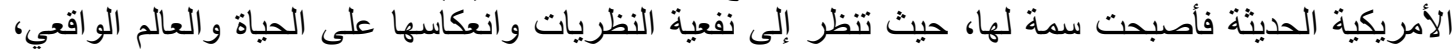
بعيدا عن مثل وعو الم الفلسفة المثالية.

9 اللغـة ودلالتها، تقريب تداولي للمصطلح البلاغي، مجلة عـالم الفكر، المجلس الوطني للتقافة و الفنون بدولة

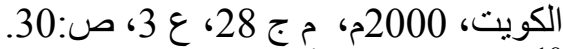
10 عيسى تومي، الأبعاد التداولية في الخطاب القر آني (بحث ماجستير نوفش في العام الدر اسي 2016/2015) 11 صلاح فضل، بلاغة الخطاب و علم النص، الكويت ، 1992، ص26 صنا2.

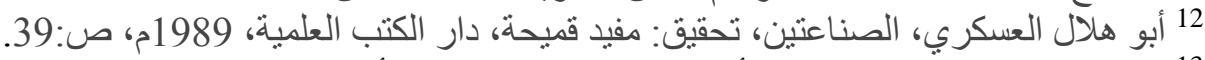

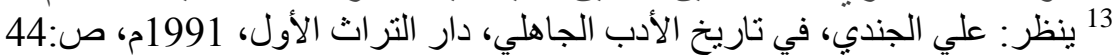

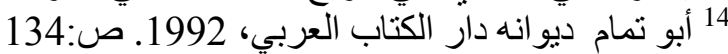

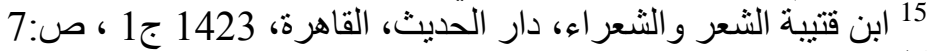
16 ينظر : محمود زيدان، وليم جيمس، دار المعارف الئ 1998، ص 182. 


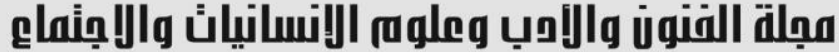

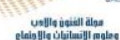

Journal of Arts, Literature, Humanities and Social Sciences www.jalhss.com

Volume (60) November 2020

العدد (60) نوفمبر 2020

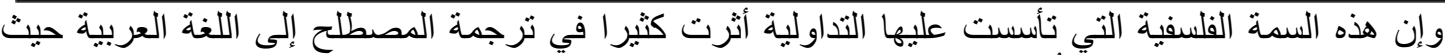

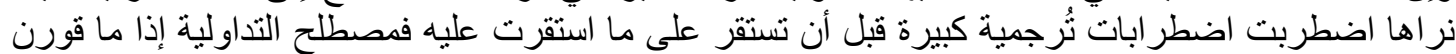

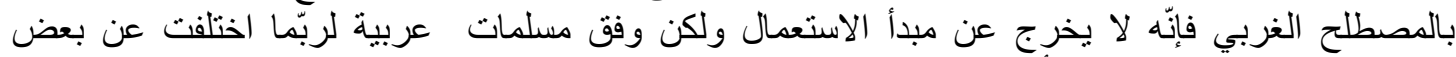

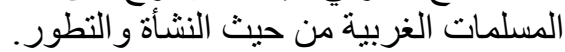

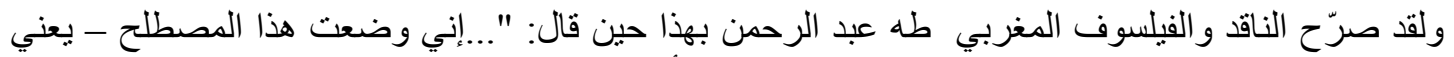

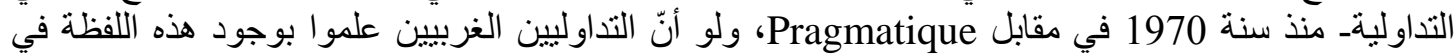

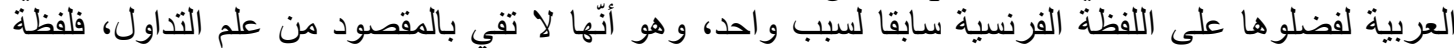

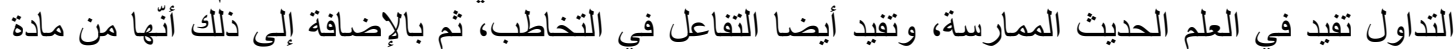
واحدة ولفظة الدلالة نفسها، يعني أنّ التداول سوف يرتبط بالدلالة؛ فإذن هذا هو التبرير العلمي الأولي لمصطلح

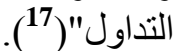

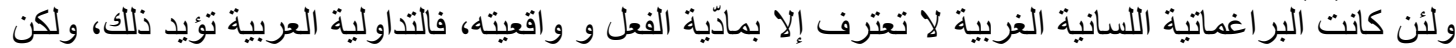

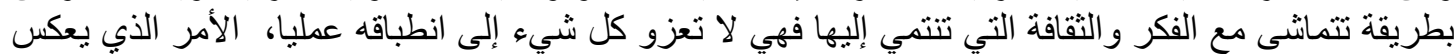
الجانب الروحي للثقافة العربية وكل مأ يتعلق بها.

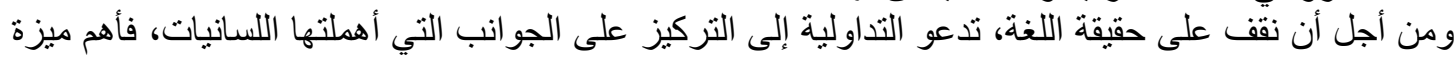

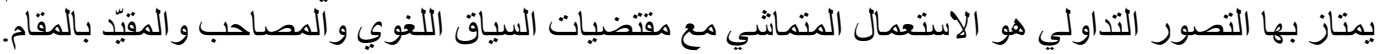

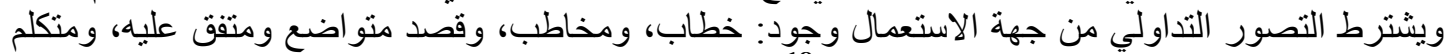

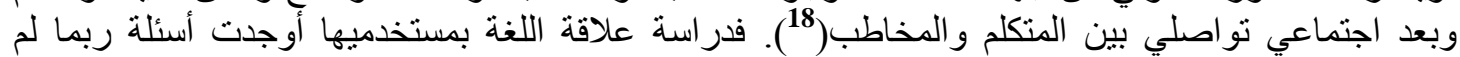

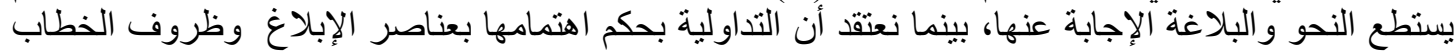

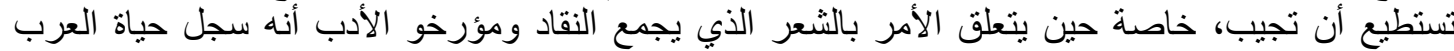
الاجتماعية بكل ما تحمله من فكر و عقائد و إديولو جيا وأحساسيس.

\section{الثعر والتداولية ومحاولة الربط الثيط}

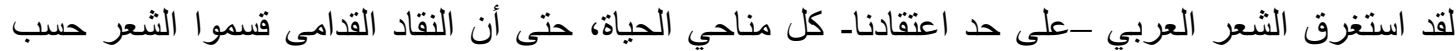

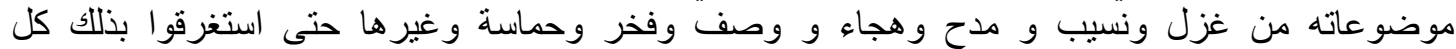

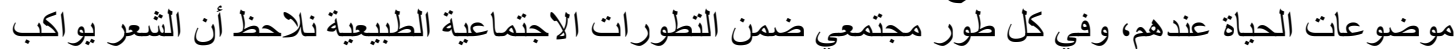

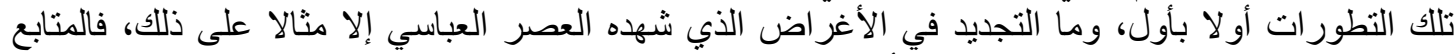

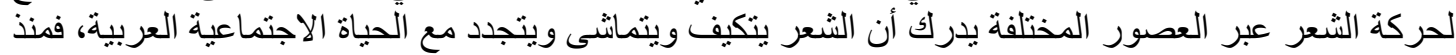

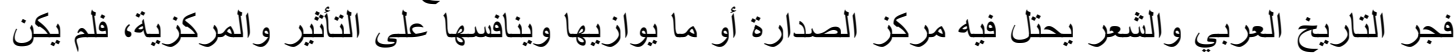

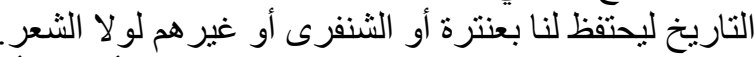

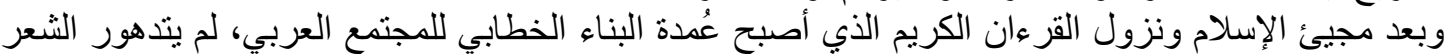

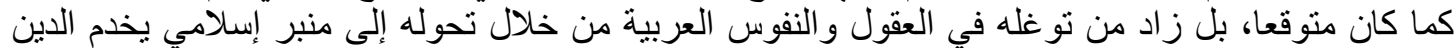

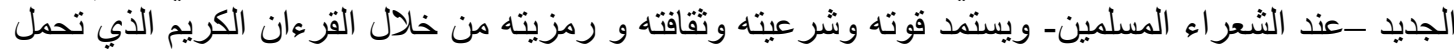

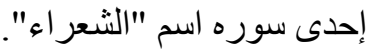

كما أنّ القرءعان الكريم ردّ على الثُعراء من غير المسلمين الذين استخدموا الثُعر في حربهم مع الإسلام ونبييه

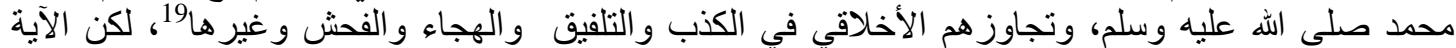

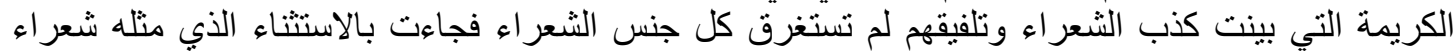
المسلمين الذين يمارسون الثنعر من أجل نصرة الدين وتكريس مكارم الأخلاق في المجتمع و التي جاء الأبي الإسلام

17 ـ طـه عبد الرحمن: الداليات و التداوليات. البحث اللساني السيميائي. كلية الآداب و العلوم الإنسانية بالرباط،

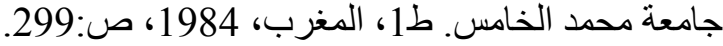
18 ي ينظر بالتفصيل إلى نعمان بوقرة: محاضر ات في في المدارس اللسـانية المعاصرة. منشور ات بـاجي مختار ،

19 ينظر . الإمام الزمحشري، الكثاف، تحقيق عبد الرازق المهدي، دار إحياء التراث العربي،2007 : ص 376 


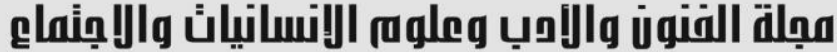

إذن فالثعر العربي شديد الارتباط بالعقلية العربية والمجتمع وشديد التكيف مع كل تطور أو تحول اجتماعي، بدءا

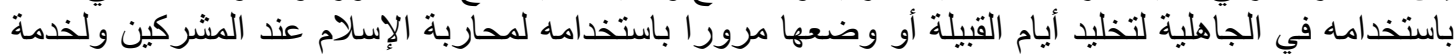

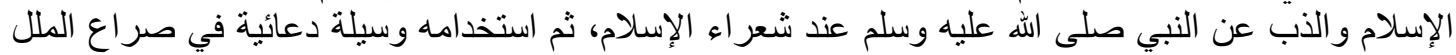

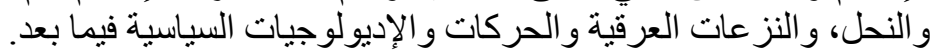

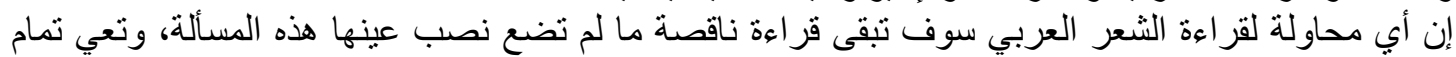

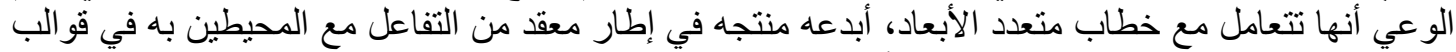

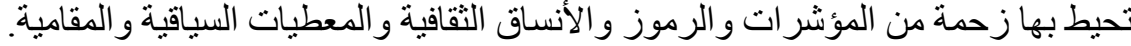

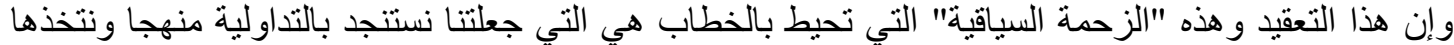

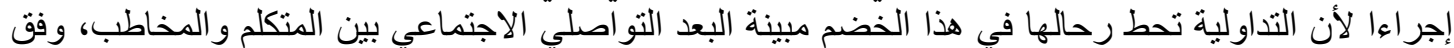

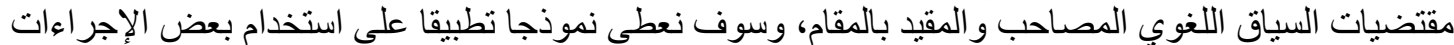

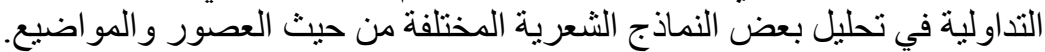

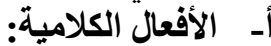

وفيما يلي بعض النماذج الثعرية التي نخضعها لإحدى أثهر النظريات التداولية التي تفترض الورقة نجاعتها في

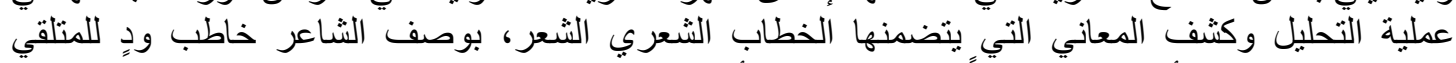

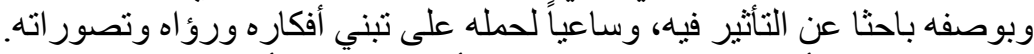

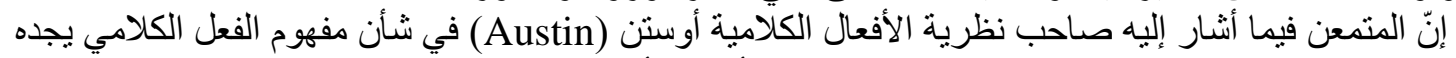

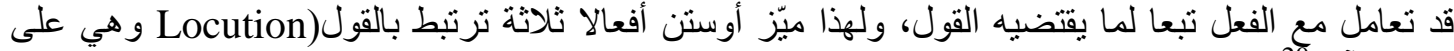

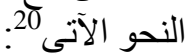

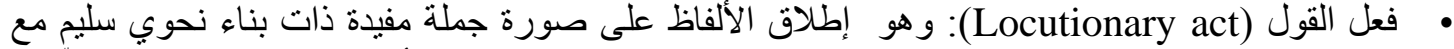

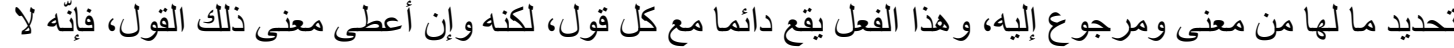

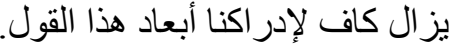

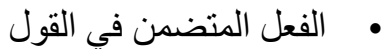

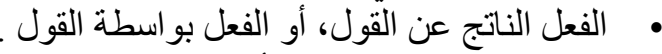

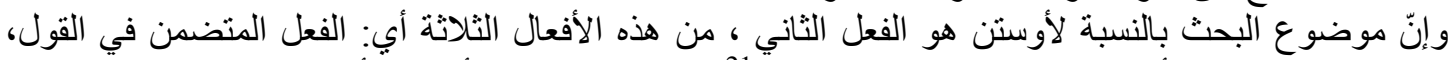

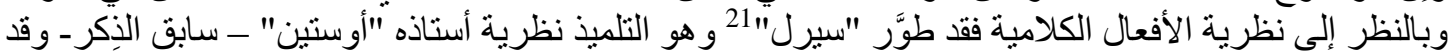

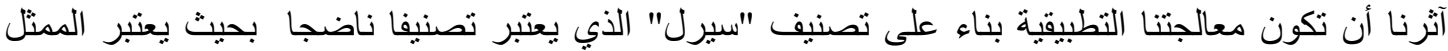

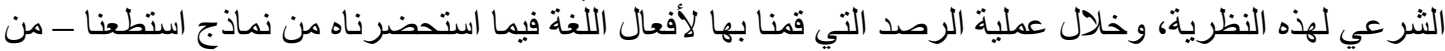

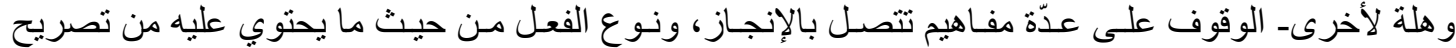

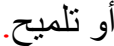
ونحن نعتقل أن إسـقاط مفـاهيم هذه النظريـة (نظريـة أفعـال الكـلام) على نص شعري بقتضي الإجابـة عن

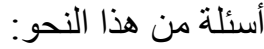

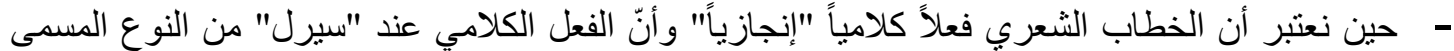

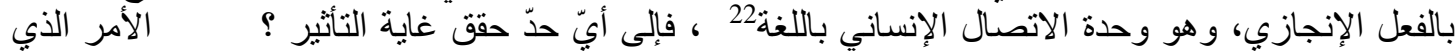

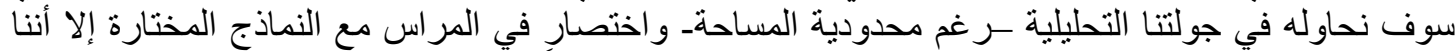

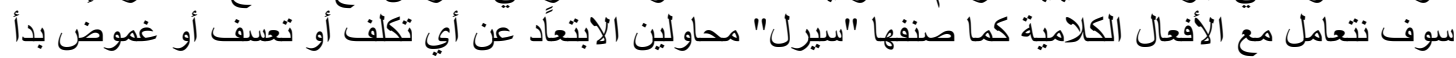
يسود المقالات و الورقات الأفعال النقدية الحديثة:

20 ينظر : طالب هاثم طبطبائي: نظرية الأفعال الكلامية. مجلة الفكر العربي المعاصر. مركز الإنماء القومي،

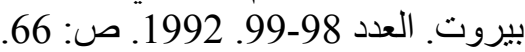

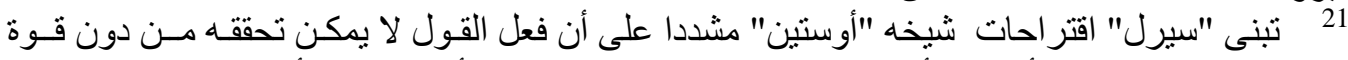

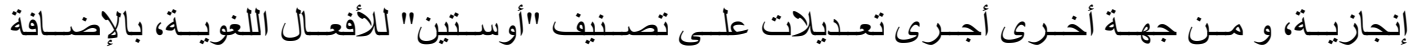

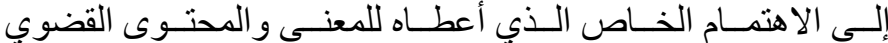

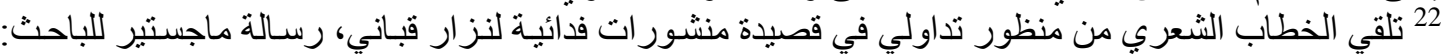

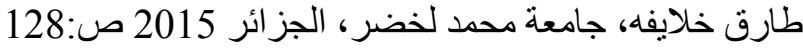




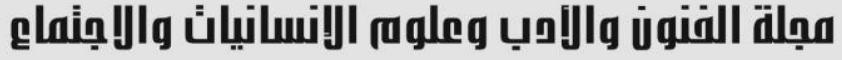

Journal of Arts, Literature, Humanities and Social Sciences www.jalhss.com

Volume (60) November 2020

\section{- الأفعال الدالة على الإثبات ( الإخباريات Assertive)

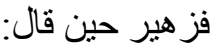

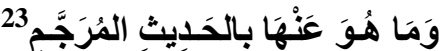

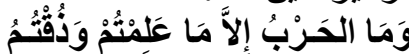

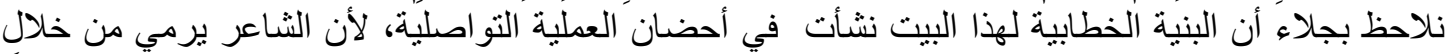

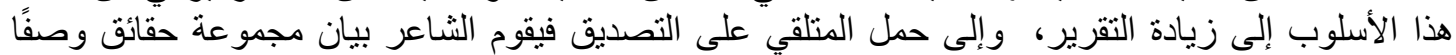

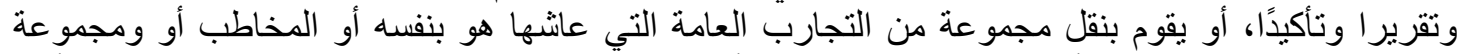

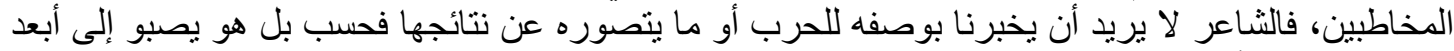

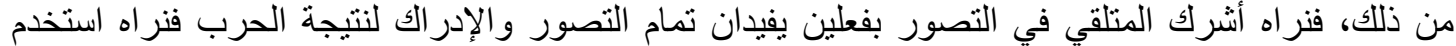

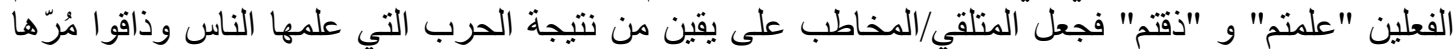

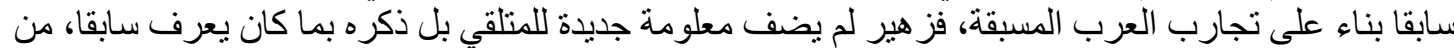

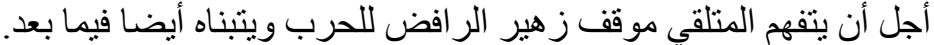
فنر اه استخدم تقنيات لغوية مختلفة من أجل تحقيق الإنجاز في البيت وفي وفي القصبيدة بشكل عام، فقد استخدم هنا

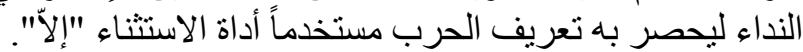

2- أفعال التوجيه ( التوجيهات Directives):

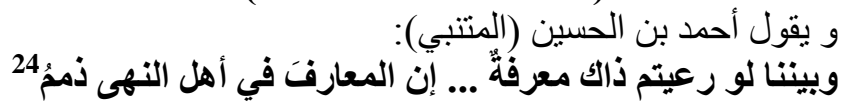

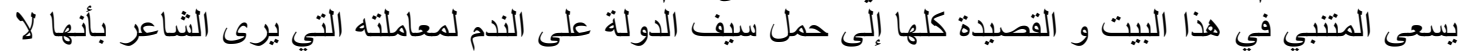

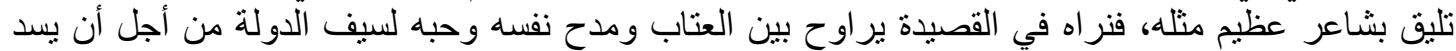
الفجوة التي خلقها أعداؤه مع صديقه الأمير.

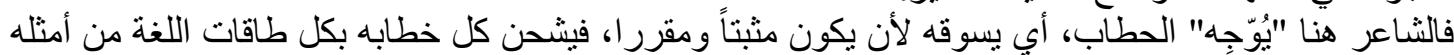

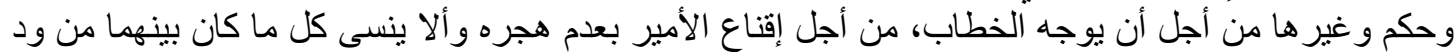
بسبب فجوة بسيطة.

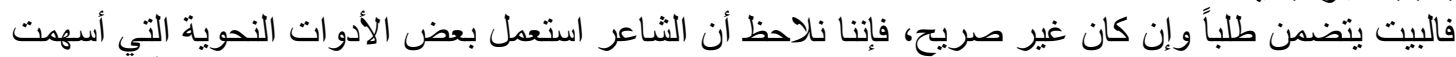

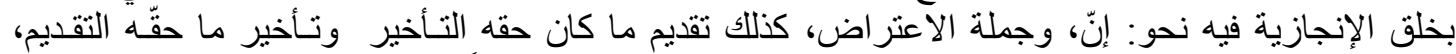

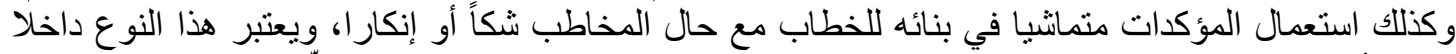

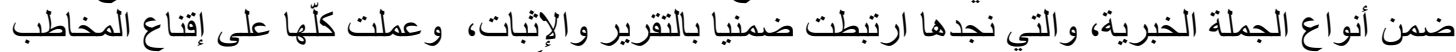

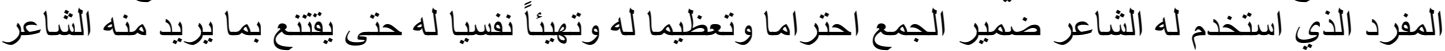

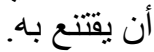

$$
3 \text { - أفعال الوعد (الالتزاميات): }
$$

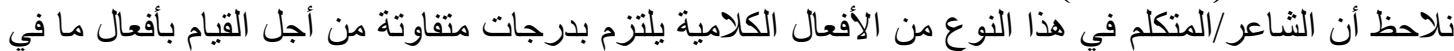

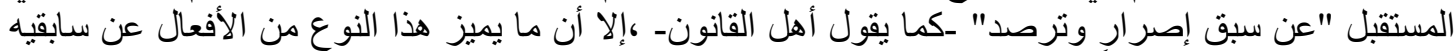

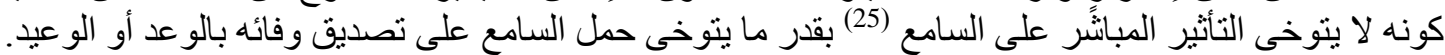

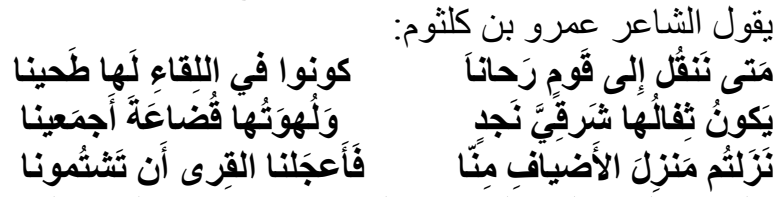

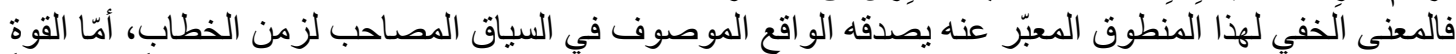

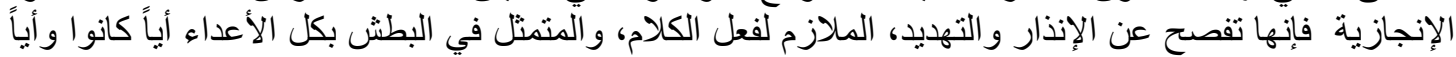

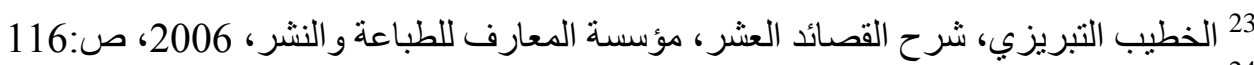

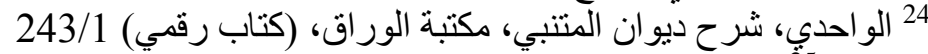

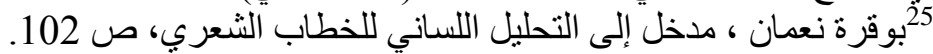




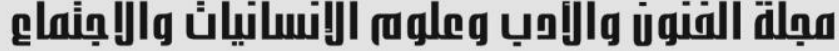

Journal of Arts, Literature, Humanities and Social Sciences www.jalhss.com

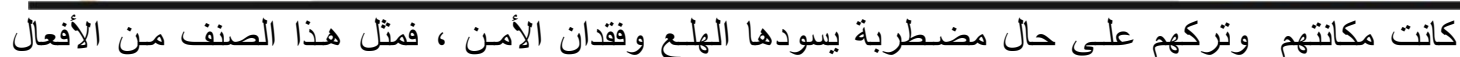

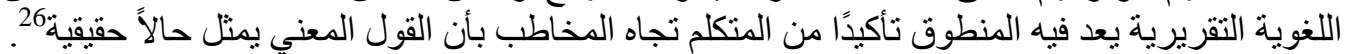

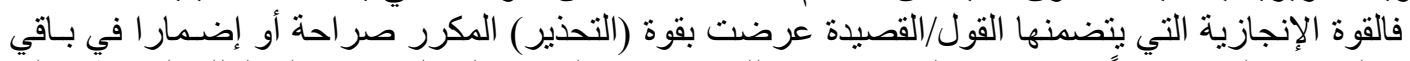

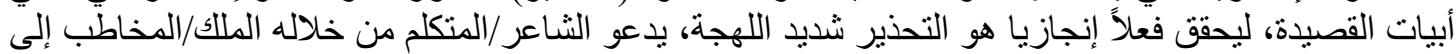

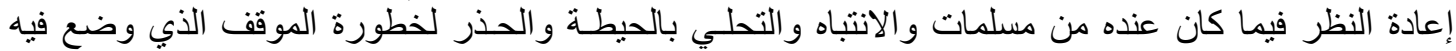

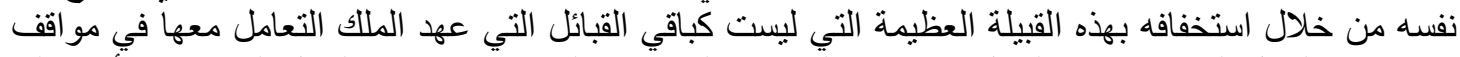

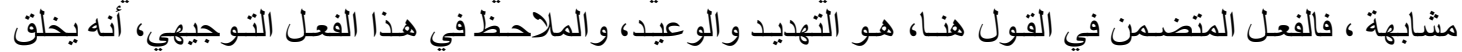

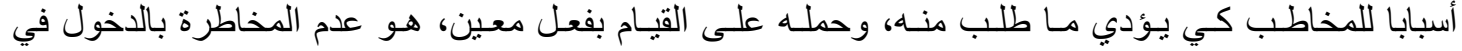
حرب مع بني تخلب.

فالثشاعر أر اد إدخال الحماس والتشجيع في نفوس أبناء قبيلته بتذكير هم بمكانتهم وحملهم على أي مو اجهة محتملة

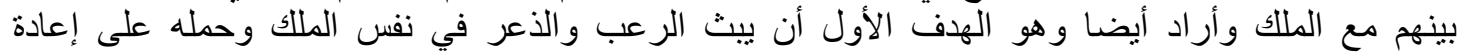

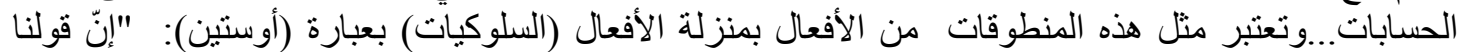

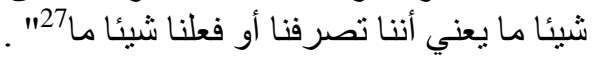

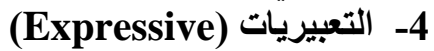
وتتجلى هذه الأفعال في التعبير عن الحالات النفسية العميقة من رثاء أو غزل أو كل ما بيخل في طائلة المشاعر

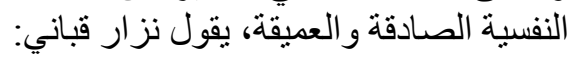

\author{
حتى خطاياه ما عادت خطاياه \\ ل لو لم نجده عليها .. لاختر عناه
}

$$
\text { أحبه في للأت أدري مـا أحب به تخيلنا }
$$

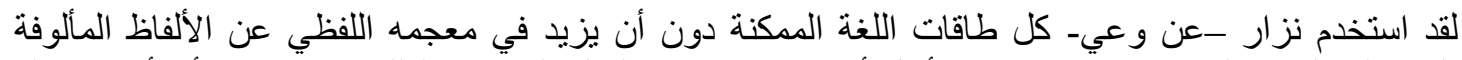

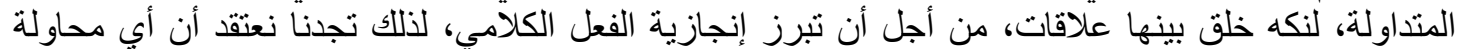

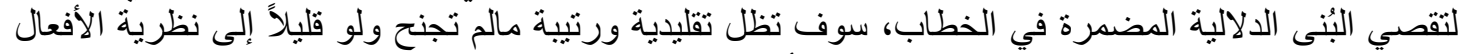

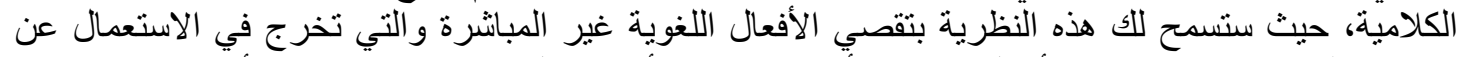

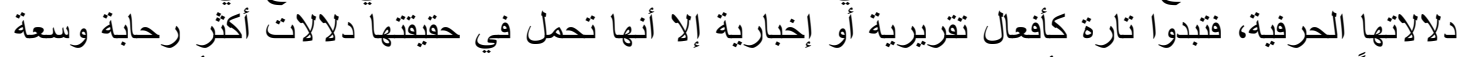

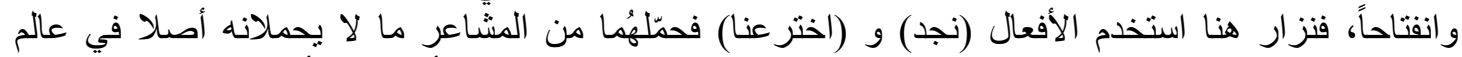

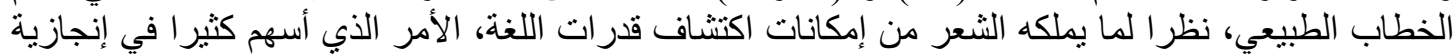
النص الثعري هذا.

وحين نقرأ أيضا نص نزار الذي يرثي فيه الزعيم العربي جمال عبد الناصر ويعاتب فيه الجماهير العربية سندرك مدى كثافة الخطاب فيه:

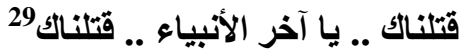

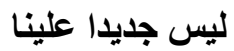
اغتيال الصحابة والأولياء

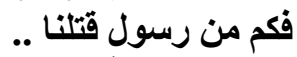

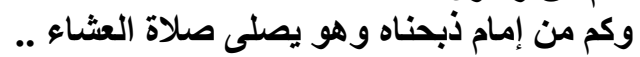

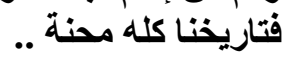

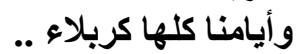

26 كلاوس برينكر ، التحليل اللغوي للنص، مدخل إلى المفاهيم الأساسية و المناهج، ت رجمة: سعيد حسن بحيري،

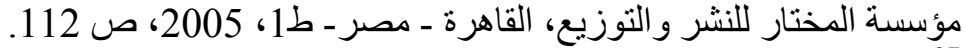

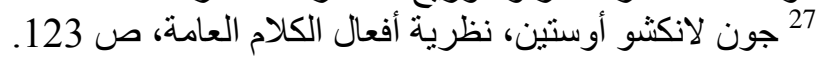

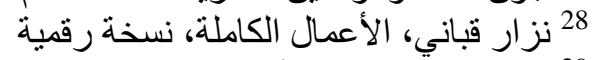
29 إسماعيل التعقباوي. الأعمال الكاملة الكاملة لنزار فبانية، مكتبة جزيرة الورد، (نسخة رقمية) 


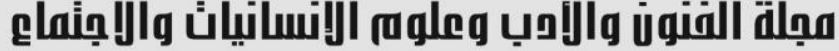

Journal of Arts, Literature, Humanities and Social Sciences www.jalhss.com

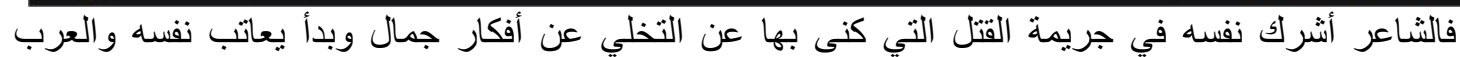

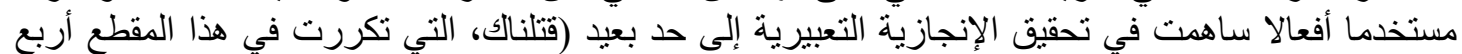

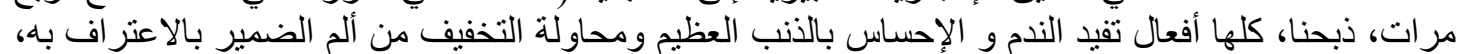
و والندم عليه.

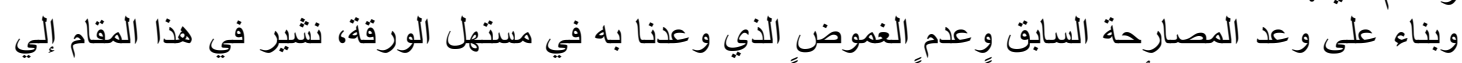

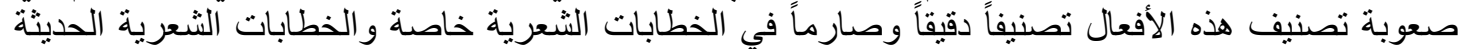

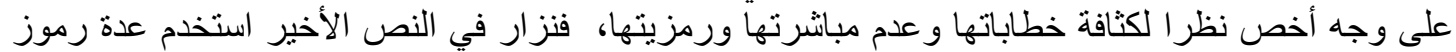

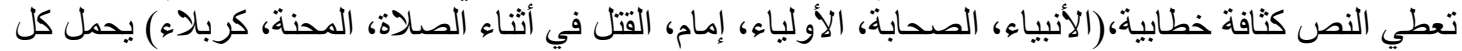
رمز من هذه الرموز شحنات دلالية كبيرة، مما يترك بنية الخطاب الثعري منفتحة على صنوف الثاء شنتى من كن التأويل.

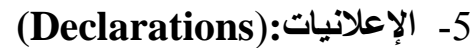

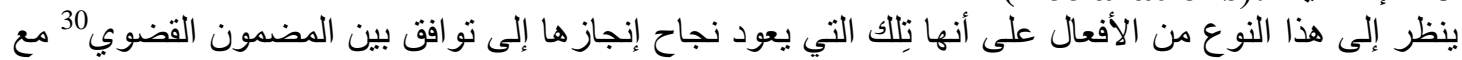

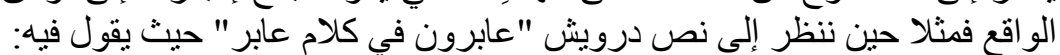

أيها المارون بين الكلمات العبات العبرة

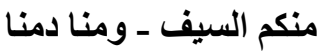

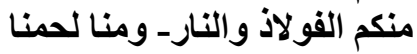

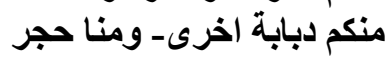
منكم قنبلة الغاز - ومنا المطرى

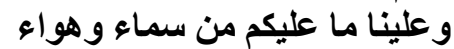
فخذوا حصتكم من دمنا وانصرفو من ماءواء

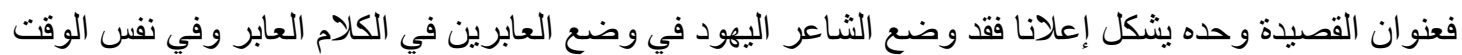

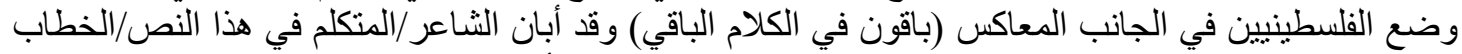

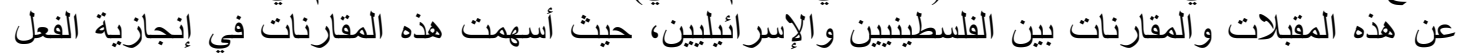

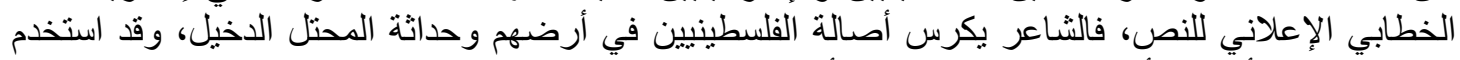

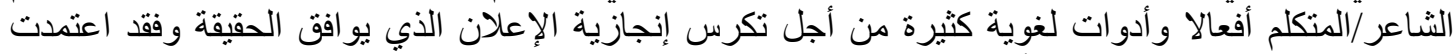

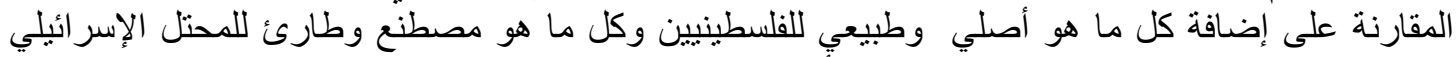
ومستخدما في ذلك كل مقدرات اللغة والرمز من أُجل تحقيق هذه الإنجازية.

الخاتمة

إنها تجربة فريدة ممتعة ومختلفة تجعلنا نشاهد المشهد الثعر من زاوية مختلفة، إن نافذة "التداولية" أو منظار ها

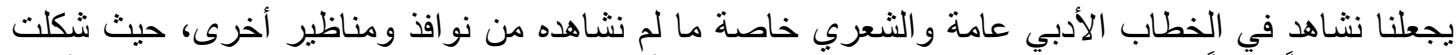

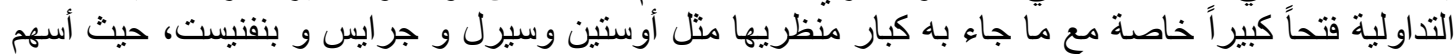

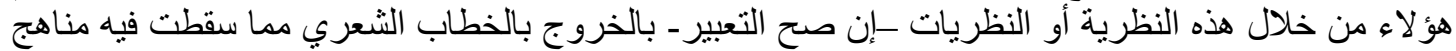
البنيوية؛ فأقحمو افي عملية التحليل عناصر تم تجاوز ها عن قصد أو عن غيره لأسباب تاريخية إبستيمولوجية من فئ فئ البحث اللساني.

30 يعرف "معجم السرديات" ـالذي أعده محمد القاضي صحبة مجمو عة من الأساتذة و الباحثين، وكذلك شكري الكائي

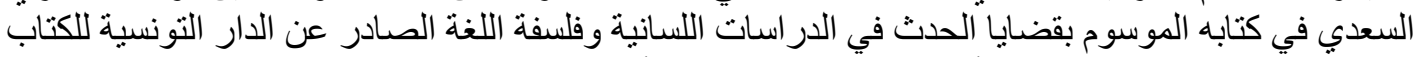

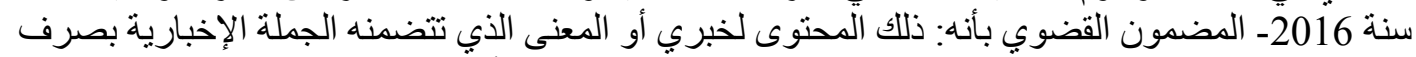

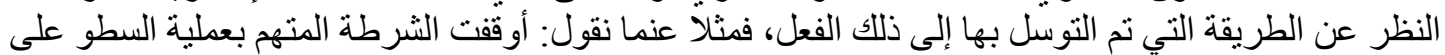

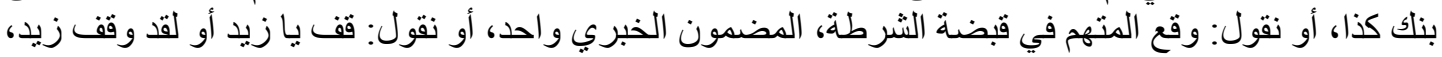

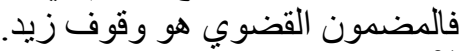

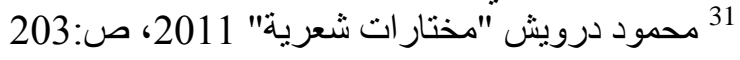




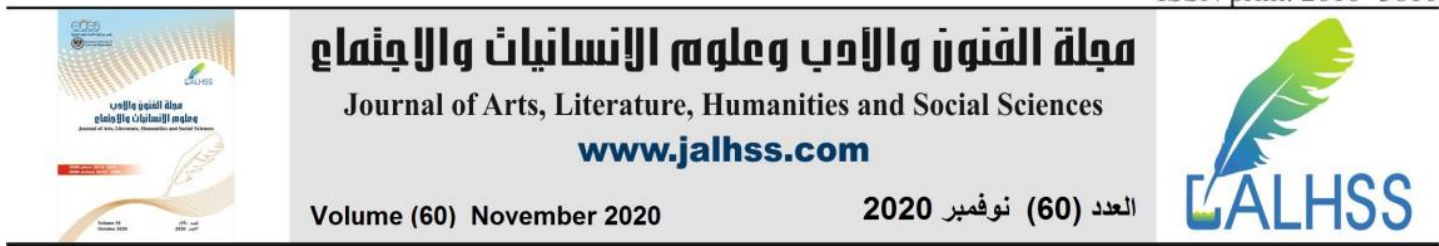

لكن الباحث الر اغب في تطبيق هذه "الإجر اءات التداولية" يو اجه صعوبة من حيث تطبيقها وتكمن تلاك الصعوبة

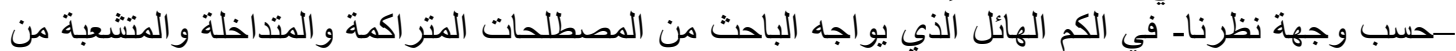

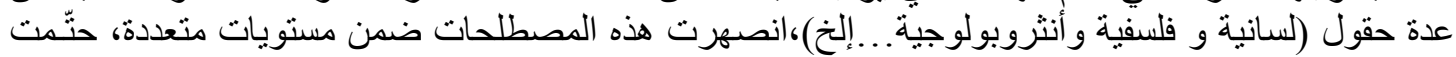

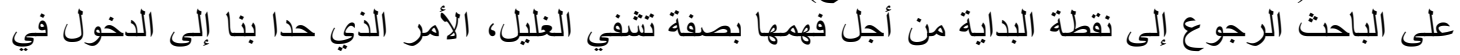

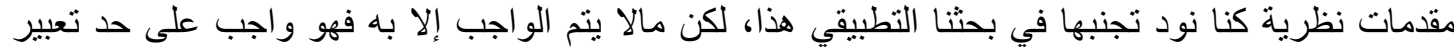
الأصولبين. و انطلاقا من مراسنا السابق نلحظ أن البحث تطور تطورا لافتا في العلوم الإنسانية وقطع أشو اطا من كبيرة

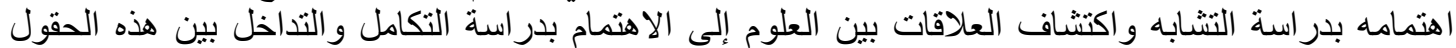

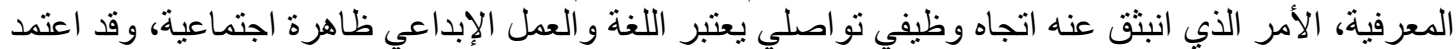

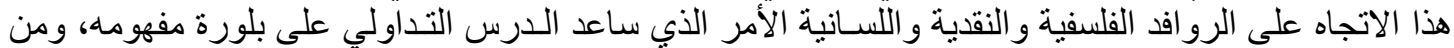
خلال إسقاط بعض هذه النظريات التداولية في هذه الورقة البحثية المختصرة خرجنا بمجموعة الألئ ملاحظات

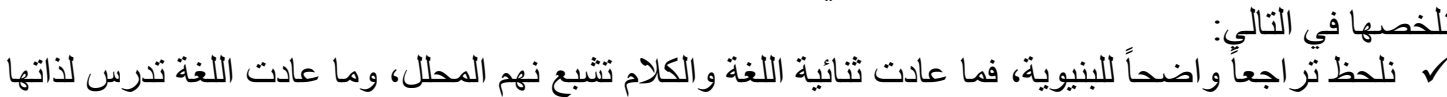

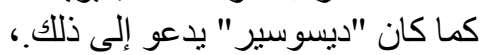

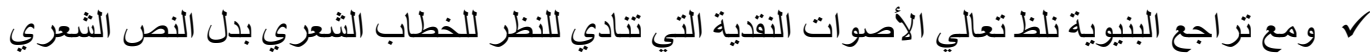

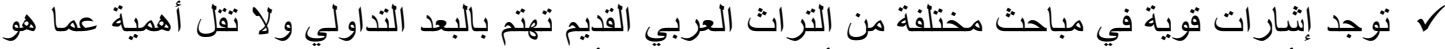

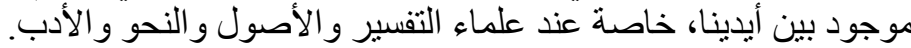

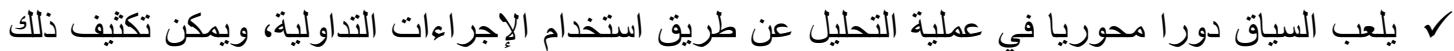

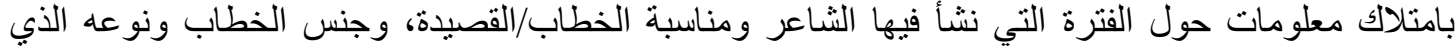

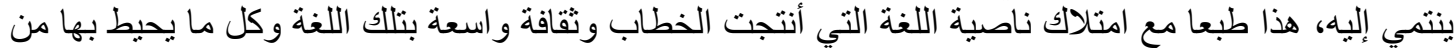

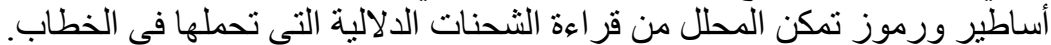

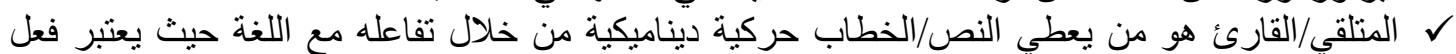

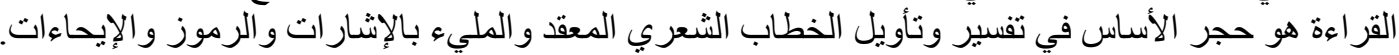

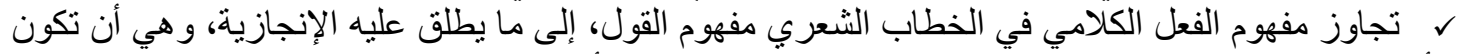

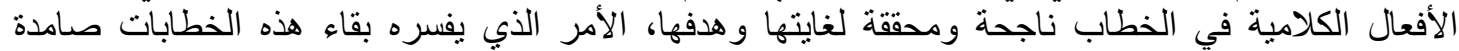

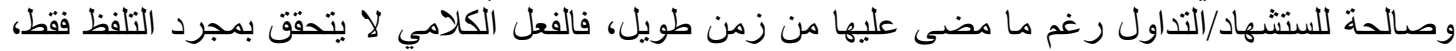

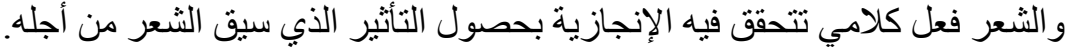

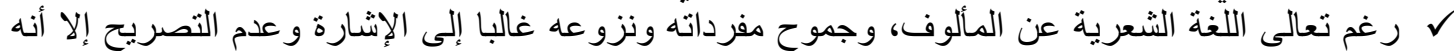

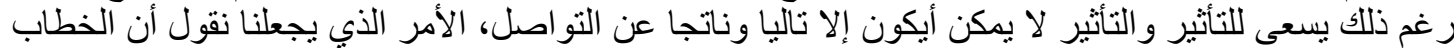

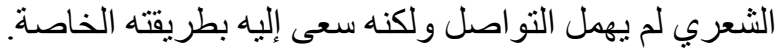

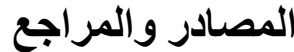

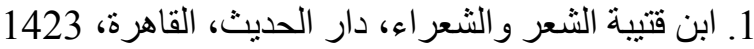

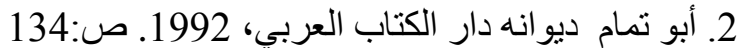

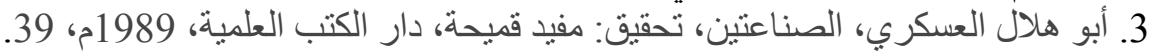

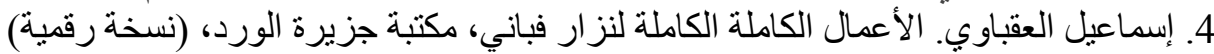

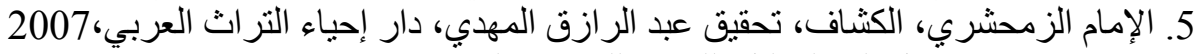

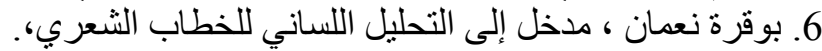
7. شكري السعدي ،الحدث في الدر اسات اللسانية وفلسفة اللغة ، الدي، الدار التونسية للكتاب ، 2016

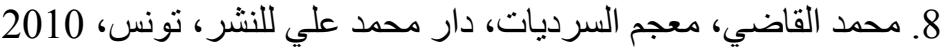
9. جون لانكثو أوستين، نظرية أفعال الكلام العامة، العئ.

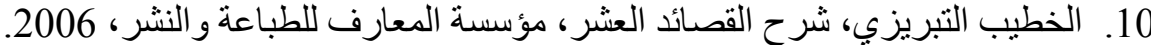

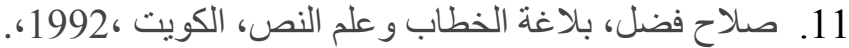




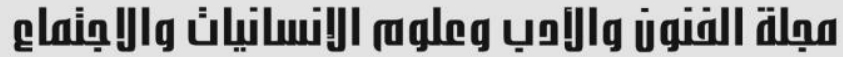

$$
\begin{aligned}
& \text { Journal of Arts, Literature, Humanities and Social Sciences } \\
& \text { www.jalhss.com } \\
& \text { Volume (60) November } 2020 \\
& \text { العدد (60) نوفمبر } 2020 \\
& \text { 12. طارق خلايفه، تلقي الخطاب الثعري من منظور تداولي في قصيدة منشورات فدائية لنزار قباني، رسالة }
\end{aligned}
$$

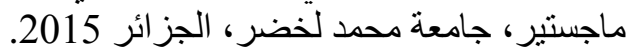

$$
\begin{aligned}
& \text { 13. طالب هاثتم طبطبائي: نظرية الأفعال الكلامية. مجلة الفكر العربي المعاصر. مركز الإنماء القومي، }
\end{aligned}
$$

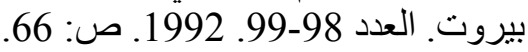

$$
\begin{aligned}
& \text { 14. طه عبد الرحمن: الداليات و التداوليات. البحث اللساني السيميائي. كلية الآداب و العلوم الإنسانية بالرباط، }
\end{aligned}
$$

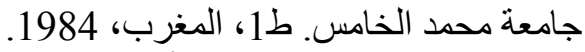

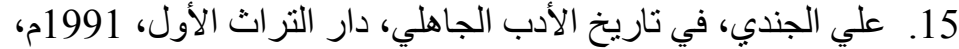

$$
\begin{aligned}
& \text { 16. عيسى تومي، الأبعاد التداولية في الخطاب القرآني (بحث ماجستير نوقش في العام الدراسي } \\
& \text { (2016/2015 } \\
& \text { 17. كلاوس برينكر، التحليل اللغوي للنص، مدخل إلى المفاهيم الأساسية والمناهج، ت رجمة: سعيد حسن }
\end{aligned}
$$

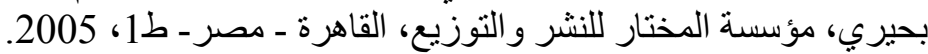

$$
\begin{aligned}
& \text { 18. أللغة ودلالتها، تقريب تداولي للمصطلح البلاغي، مجلة عالم الفكر ، المجلس الوطني للثقافة والفنون بدولة }
\end{aligned}
$$

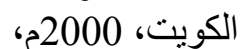

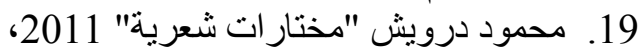

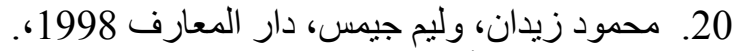

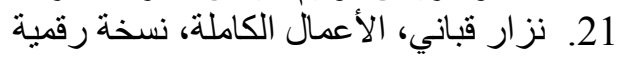

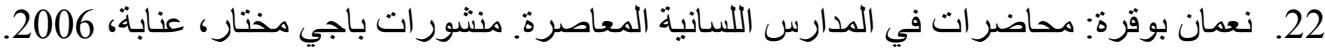

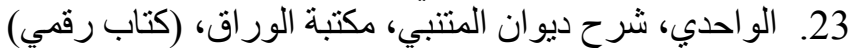

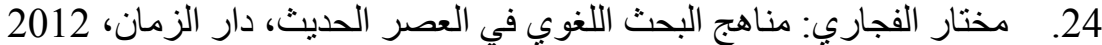

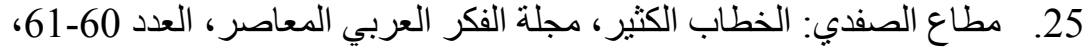

$$
\begin{aligned}
& \text { 26. محمد عابد الجابري تكوين العقل العربي، ط 14، } 2014 .
\end{aligned}
$$

\section{References}

1. Ibn Qutaybah poetry and poets, Dar Al-Hadith, Cairo, 1423

2. Abu Tamam, his collection of the Arab Book House, 1992. p .: 134

3. Abu Hilal Al-Askari, The Two Industries, edited by: Mufid Qumaiha, Dar AlKutub Al-Ilmiyya, 1989 AD, 39

4. Ismail Al-Aqbawi. The Complete Works of Nizar Vebani, The Rose Island Library, (digital version)

5. Imam Al-Zamahhari, Al-Kashaf, edited by Abd Al-Raziq Al-Mahdi, Arab Heritage Revival House, 2007

6. Bougara Naaman, an introduction to the linguistic analysis of poetic discourse.

7. Shukri Saadi, The event in linguistic studies and the philosophy of language, Tunisian Book House, 2016

8. Muhammad Al-Qadi, Dictionary of Narrations, Muhammad Ali Publishing House, Tunis, 2010

9. John Lancashoe Austin, General Speech Verbs Theory.

10. Al-Khatib Al-Tabrizi, Explanation of the Ten Poems, Al-Ma'arif Foundation for Printing and Publishing, 2006.

11. Salah Fadl, Rhetoric and Textual Science, Kuwait, 1992.

12. Tariq Khleifeh, Receiving the Poetic Discourse from a deliberative perspective in the poem by Nazar Qabbani Feda Manuscripts, Master Thesis, Mohamed Lakhdar University, Algeria 2015. 

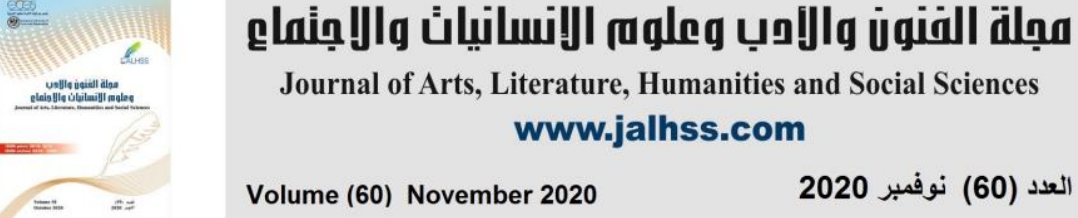

13. Talib Hashem Tabatabai: The Theory of Verbs. Journal of Contemporary Arab Thought. National Development Center, Beirut. Issue 98-99. 1992. p: 66.

14. Taha Abdel-Rahman: Dalmatians and deliberations. Semiotic Linguistic Research. Faculty of Arts and Humanities in Rabat, Mohammed V University. I-1, Morocco, 1984.

15. Ali Al-Jundi, In the History of Pre-Islamic Literature, First Heritage House, 1991 $\mathrm{AD}$,

16. Issa Tomei, The deliberative dimensions of the Qur'anic discourse (MA research discussed in the 2015/2016 academic year)

17. Klaus Brinker, Linguistic Analysis of the Text, An Introduction to Basic Concepts and Methods, translated by: Said Hassan Beheiry, Al-Mukhtar Foundation for Publishing and Distribution, Cairo - Egypt - 1st Edition, 2005.

18. Language and its connotations, a deliberative approximation of the rhetorical term, World of Thought Magazine, The National Council for Culture and Arts in the State of Kuwait, 2000 AD,

19. Mahmoud Darwish, "An Anthology of Poetry" 2011, 20. Mahmoud Zidan, William James, Dar Al Maaref 1998 ,.

21. Nizar Qabbani, Complete Works, digital version

22. Nouman Bouguerra: Lectures on contemporary linguistic schools. Publications of Badji Mokhtar, Annaba, 2006.

23. Al-Wahidi, Explanation of Diwan Al-Mutanabi, Al-Warraq Library, (digital book) 24. Mukhtar Al-Fajari: Linguistic Research Methods in the Modern Era, Dar AlZaman, 2012

25. Muta'a Al-Safadi: The Much Discourse, Journal of Contemporary Arab Thought, Issue 60-61,

26. Muhammad Abed Al-Jabri, Forming the Arab Mind, 14th Edition, 2014. 